\title{
Performance analysis of thermosyphon heat exchanger charged with ZnO for heat recovery application
}

\author{
Makarand Dharmadhikari* and R.K.Patil \\ PVPIT, Bavdhan, Pune-411021, Maharashtra, India \\ Accepted 15 June 2016, Available online 20 June 2016, Special Issue-5 (June 2016)
}

\begin{abstract}
A heat pipe is a device that can transport large quantities of heat with a very small difference in temperature between the hot ends to the other end. In this study, the concept of the evaporation process of heat pipe is applied in order to perform heat transport process. The objective of this study is to compare the efficiency between the heat pipe with water as a working fluid and nanofluid at various nano fractions in order to perform the heat transport process. The working fluid of heat pipe had been divided into three samples as water, $1 \%$ of nanofraction and $2 \%$ of nanofraction. These three set of heat pipes were made without the wick but dealing with inclination angle of $90^{\circ}$ to see the performance of the heat pipe. All sets of heat pipes were built by the total length of $550 \mathrm{~mm}$ length and $16 \mathrm{~mm}$ diameter using copper as the material of pipe. Gravity pumping was used with the inclination angle to pump back the working fluid back to the evaporator section. To achieve the objective of this study, all sets of pipes were studied experimentally to find the most efficient between all sets of heat pipe. The important parameter involves in this study are the heat transport and Effectiveness. After performing the experimentation the objective of this case study is achieved, which showed the set of heat pipe is more efficient which is having $2 \%$ nanofraction.
\end{abstract}

Keywords: Thermosyphons, Heat Pipe heat exchanger, ZnO, Heat transport capacity, Effectiveness.

\section{Introduction}

A heat pipe is a device which can transfer large quantities of heat with a very small temperature difference in between the one end and the other end. In other words, it is a simple device that can quickly transfer heat from one point to another. They are also referred to as the superconductors of heat as they possess an extra ordinary heat transfer rate and with almost no heat loss.

\subsection{Classification and Application}

The Figure 1 indicates the potential energy content magnitude of the three different temperature categories of waste heat based on cooling the exhaust air stream to a temperature of $77^{\circ} \mathrm{F}$.

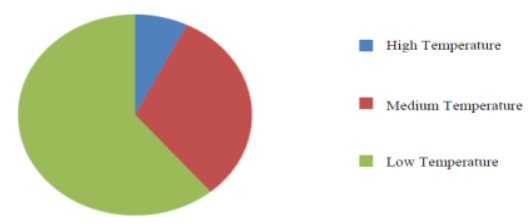

Figure 01 Unrecovered waste heat in different temperature groups
Heat pipe heat exchangers have the form of normal finned coils, but each successive tube is not dependent and not connected to other tubes. Each and every tube is built with an internal capillary wick material. The tube is evacuated, filled with a compatible fluid depending upon the temperature range and individually sealed. With the tubes installed straight, one half of the heat exchanger will work like an evaporator and the other half sections works like a condenser. The high temperature air stream passes throughout the evaporator half of the unit and the low temperature air stream passes from the condenser half. The high-temperature air stream passes over one half of all the tubes. As the working fluid is heated and vaporized in the evaporator section, the internal vapor pressure gradient drives the gas to the condenser section of the tube. In the condenser section, the fluid releases the latent energy of vaporization as it condenses, therefore heating the low-temperature air stream. Liquid returns to the evaporator end through the internal wick.

Heat pipes are generally constructed of copper tubes with aluminum fins. Tubes are installed vertically or horizontally, but tilting the tubes in one direction or the other can control the amount of heat transfer.For instance, working the heat pipe unit with the evaporator section lower than the condenser side improves the liquid refrigerant flow back to the

*Corresponding author: Makarand Dharmadhikari 
evaporator and heat transfer capacity increases. Reversing the arrangement retards liquid refrigerant flow and reduces capacity. Figure 02 shows the heat pipe heat exchanger.

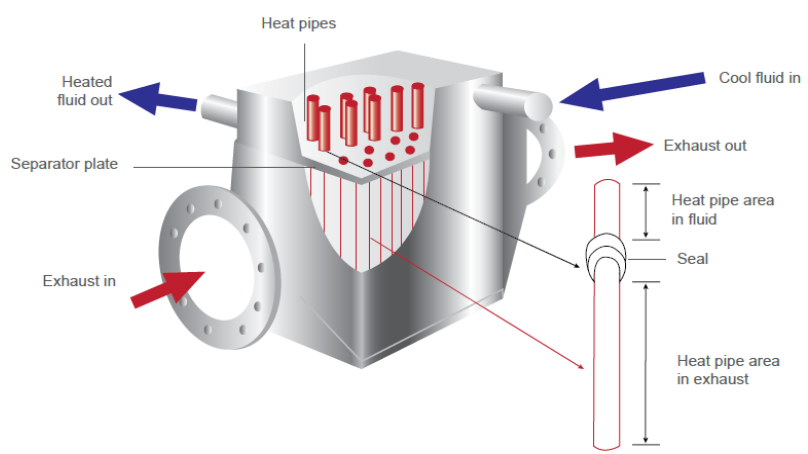

Figure 02 Heat pipe heat exchanger

Heat pipes are valuable for sensible heat transfer only. Some latent benefit can be achieved if the hot, humid outdoor air stream is cooled adequately to condense moisture on the evaporator side of the unit. Heat pipes can be installed in such a way that cross contamination between the two air streams is near zero.

These exchangers provide a simple, efficient and compact method of heat recovery from air-to-air. They resemble conventional heating and cooling coils, but have a number of important differences. First, a partition divides the exchanger in to two sections, thus ensure the partition of supply and exhaust airflows. Another thing is each heat pipe is an individual heat exchanger not dependent on any other part to make sure operation. The exchanger manufactured by these heat pipes is a counter flow design. In operation, exhaust air is passed transversely one section of the exchanger (evaporator side) and supply air is ducted in oppose flow direction across the other side. Heat is passed from the hot air stream to the cold air stream by the heat pipes. While the heat pipe can pull through up to $82 \%$ of exhaust air heat under perfect conditions, the economical heat recovery rate is between $65 \%$ and $50 \%$. This represents a tremendous saving of energy.

A heat pipe is an outstanding heat conductor; one end of a heat pipe is the condensation side, and the other end is the evaporation end. When the evaporation side is heated, the liquid in the heat pipe evaporates quickly. This vapor releases its heat at the condensation side, which has a small vapor pressure difference, and condenses back into liquid.

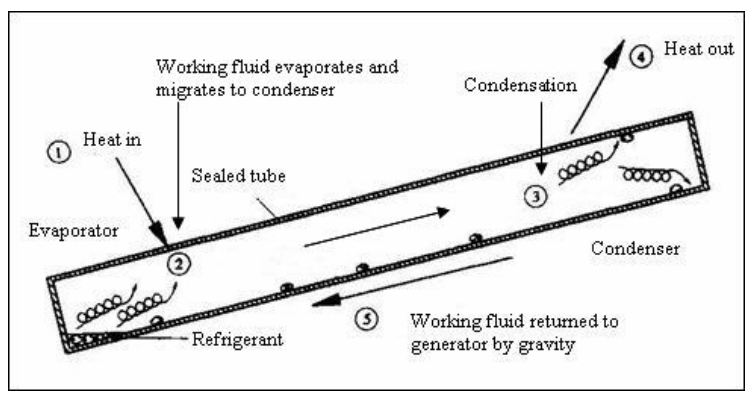

Figure 03 Heat pipe using gravity pumping
The condensed liquid in the condensation side then flows back to the evaporation side along the inner wall of the heat pipe and perform endothermic evaporation in the evaporation side. The heat transfer of a working fluid used in heat pipe that changes phases in a constant endothermic and exothermic cycle, giving the heat pipe excellent heat transfer performance.

\section{Literature Review}

Habert et al. stated the thermosyphons systems are only partially filled with the working fluid. The amount of fluid filling, i.e. the filling ratio, is defined as the ratio of the total volume of fluid in the system to the total volume of the system. The filling ratio is an important factor that highly influences the performance of a thermosyphons system and studies have shown that an optimum value or an optimum range can be found. This is illustrated schematically in figure 04 below. When the filling ratio is too low, the liquid film in the micro channels dries-out prematurely, resulting in superheating which causes large temperature gradients in the base plate. On the other hand, when the filling ratio is too high, liquid accumulates in both the condenser and the evaporator. This condition is referred to as flooding. It reduces the heat exchanging components and results in high levels of sub cooling which leads to temperature gradients in the base plate. Therefore it is essential to identify the optimum filling range for each thermosyphons system.

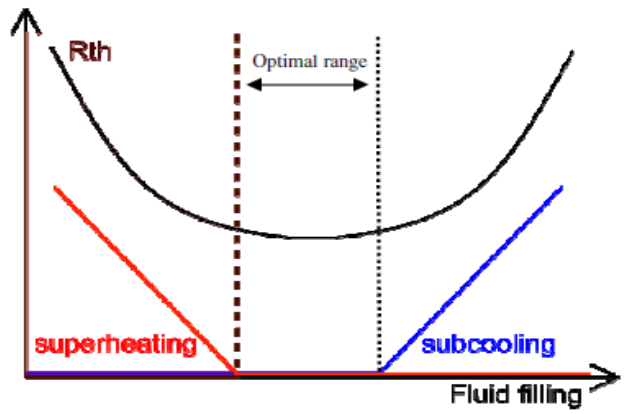

Figure 04 Fluid filling curve (Habert, 2012)

Morrison et al. studied on thermosiphons have been used successfully in several applications. Thermosiphons have often been used for solar heat transfer applications especially for solar water heating. In a solar water heater application, a sloped evacuated glass pipe is filled with a working fluid. As a result of gravity, the working fluid collects at the bottom of the pipe. The sun supplies solar thermal energy to the bottom of the pipe vaporizing the working fluid. The now less dense vapor rises to the top of the pipe where it exchanges heat with a water tank. As a result of this heat exchange, the vapor condenses and drips down the side of the pipe and the cycle repeats.

Heuer et al. works on the same principle has been applied to ground source heat transfer as well. A large scale thermosiphon array was installed in 1969 as part of the Trans-Alaskan pipeline. The pipeline supports were built mostly above permafrost. To keep the 
supports stable, the permafrost had to be kept frozen. To do this, thermosiphons were placed inside the supports to take heat out of the ground. More than 124,300 thermosiphons were installed as part of this project.

Sorensen et al, this project was reviewed, and it was found that several of the thermosiphons had experienced a reduction in heat transfer performance due to an accumulation of no condensable gases at the top of the thermosiphons. This phenomenon, known as cold topping, was a result of corrosion or chemical dissociation of the working fluid, anhydrous ammonia. Thermosiphons have also been implemented successfully in space heating applications. In Belarus, thermosiphons have been used to keep greenhouse temperatures above freezing.

Vasiliev et al., In Northern Austria, a corrugated steel thermosiphon was installed to 15 heats a residential building. The working fluid of this particular thermosiphon was carbon dioxide $\left(\mathrm{CO}_{2}\right)$. The thermosiphon was placed in a borehole that had been drilled down to a depth of 100 meters. An inline pump was installed for increased fluid circulation. During the winter of 2006-2007, the thermosiphon was able to successfully heat the home with an average COP of 4.1.

Ochsner et al. shows some experimental work with reversible thermosiphons has also been conducted at the University of Utah. In 2009, a COMSOL computer simulation of a thermosiphon array indicated that compared to a U-tube GSHP, the thermosiphon design would increase heat transfer by $250 \%$. This finding indicates that thermosiphon boreholes need not be as deep as U-tube boreholes. If a U-tube system requires a borehole of 250 feet, the thermosiphon would only require a 100 foot borehole. To verify this result, a small scale array of seven thermosiphon prototypes was installed at depths of 10 feet. As expected, temperature readings showed that thermal energy was successfully being transferred from the ground to the thermosiphon system.

\section{Development of experimental Set up}

As described earlier proposed work aims to investigate the experimental performance of heat pipe heat exchanger charged with $\mathrm{ZnO} / \mathrm{H}_{2} \mathrm{O}$ Hybrid Nanofluid under variable source temperatures and mass flow rate. With broad perspective this study aims to investigate the feasibility of TPCT HPHX from low temperature waste heat source. In order to achieve the objectives stated above it has been decided to design and develop the experimental system as shown in following figure 05. Heat pipe heat exchangers are devices that made the exchange of energy (waste heat) from a waste heat source to a colder source. Fig. 05 shows the schematic diagram of the experimental system. The system is composed of three major parts: air heater (for waste hot air preparation), heat pipe heat exchanger (with hybrid nanofluid) and devices for measurement and control of parameters. In the installation there are two circulating fluids: the hot agent (waste air) in the lower chamber of the heat exchanger and the cold agent (cold air) in the upper chamber of the heat exchanger. The heat pipe heat exchanger was equipped with ten heat pipes arranged vertically at an angle of $90^{\circ}$. The working fluid used in heat pipe is $\mathrm{ZnO}$ nanofluid.

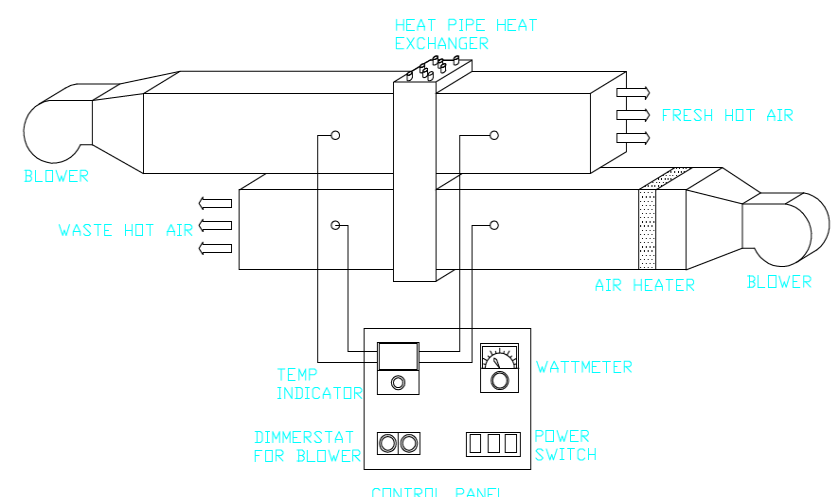

Figure 05 Schematic diagram of the experimental set up.

Fig Contents: Heat pipe heat exchanger, Blower, Air heater, Temperature Indicator, Wattmeter, Dimmerstat, Power switch

\section{A. Design Procedure for Proposed Heat Pipe}

Heat pipes undergo various heat transfer limitations depending on the working fluid, the dimensions of the heat pipe, and the heat pipe operational temperature.

\section{1) heat pipe limits}

The various heat pipe limits calculated considering the operating temperature and parameters related to heat pipe are shown in figure 06 . For heat pipe parameters mentioned above the axial heat flux under variable operating temperatures are calculated for different mentioned above i.e. viscous limit, boiling limit, entrainment limit and sonic limit.

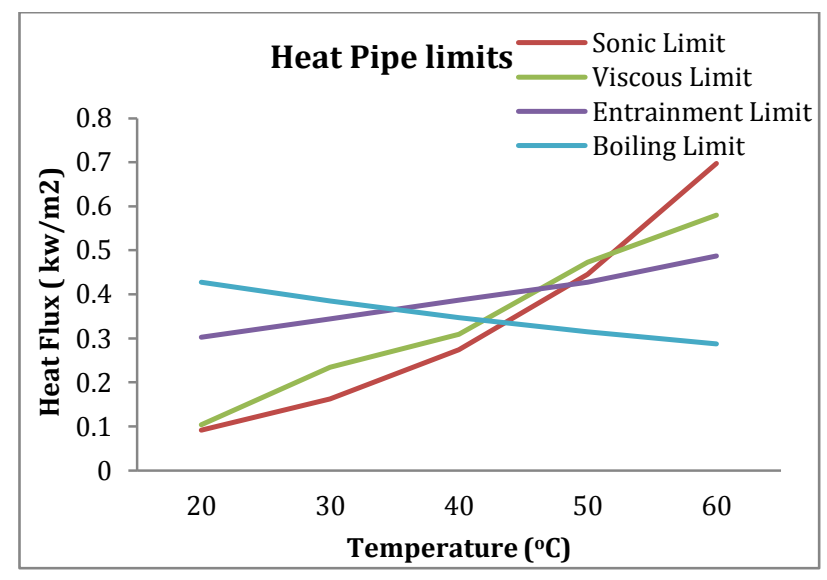

Figure 06 Heat pipes Limits for various operating temperatures 


\section{Results and Discussion}

4.1 Calculation of Effectiveness $(\epsilon)$ : For various inlet gas temperatures, effectiveness is calculated for thermosyphons heat pipe heat exchanger. Results are plotted heat gain verses air velocity. Velocity of air at condenser and evaporator section is same and vary as $1 \mathrm{~m} / \mathrm{s}, 2 \mathrm{~m} / \mathrm{s}, 3 \mathrm{~m} / \mathrm{s}, 4 \mathrm{~m} / \mathrm{s}$ and $5 \mathrm{~m} / \mathrm{s}$. Effectiveness is calculated for three types of working fluid as water, $1 \%$ nanofluid and $2 \%$ nanofluid.

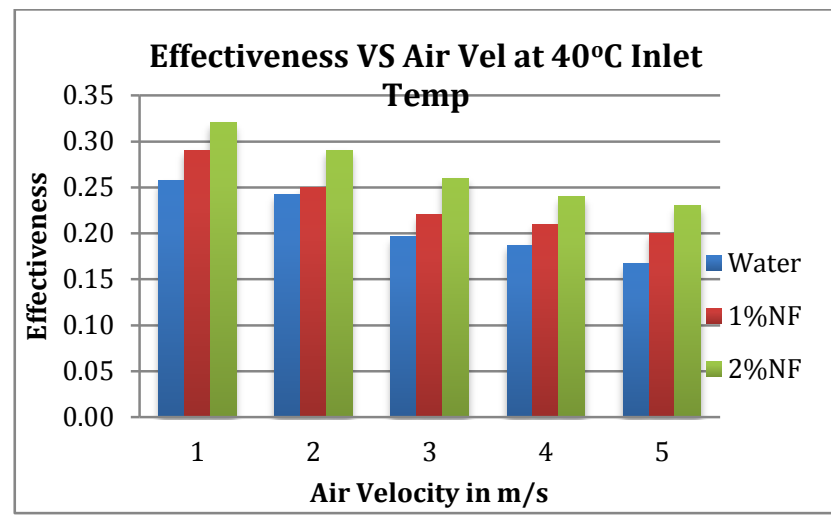

Figure 07 Effectiveness $(\epsilon)$ VS Air velocity at $40^{\circ} \mathrm{C}$ inlet gas temp.

The above graph of Effectiveness ( $\epsilon$ ) VS Air velocity at $40^{\circ} \mathrm{C}$ inlet gas temperature shows that as air velocity increases effectiveness decreases. $2 \%$ nanofraction shows better results than $1 \%$ nanofraction and water. $11.52 \%$ and $27.72 \%$ are the increment in effectiveness at $1 \%$ nanofraction and $2 \%$ nanofraction with respect to water.

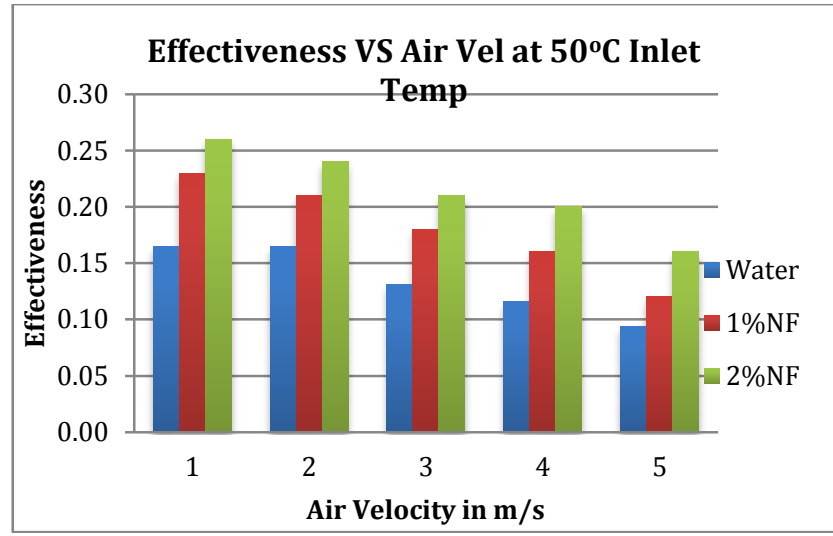

Figure 08 Effectiveness ( $\epsilon$ ) VS Air velocity at $50^{\circ} \mathrm{C}$ inlet gas temp.

The above graph of Effectiveness ( $\epsilon$ ) VS Air velocity at $50^{\circ} \mathrm{C}$ inlet gas temperature shows that as air velocity increases effectiveness decreases. $2 \%$ nanofraction shows better results than $1 \%$ nanofraction and water. $34.20 \%$ and $59.55 \%$ are the increment in effectiveness at $1 \%$ nanofraction and $2 \%$ nanofraction with respect to water.

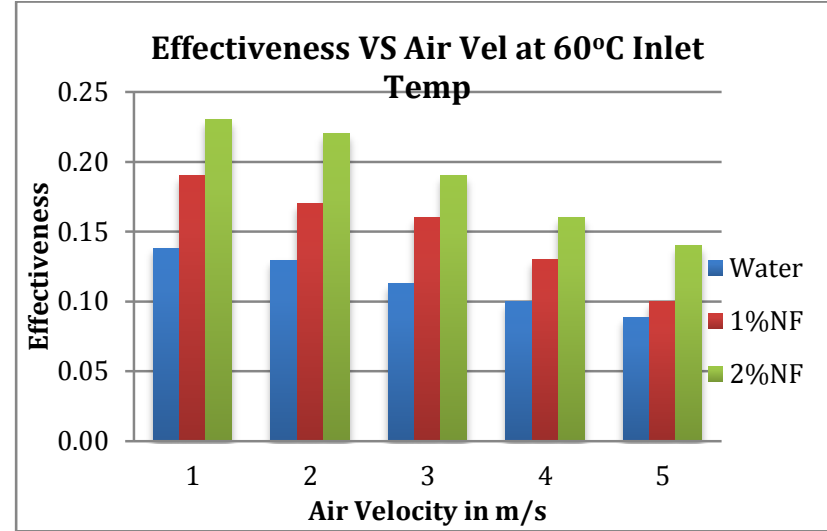

Figure 09 Effectiveness ( $€$ ) VS Air velocity at $60^{\circ} \mathrm{C}$ inlet gas temp.

The above graph of Effectiveness ( $\epsilon$ ) VS Air velocity at $60^{\circ} \mathrm{C}$ inlet gas temperature shows that as air velocity increases effectiveness decreases. $2 \%$ nanofraction shows better results than 1\% nanofraction and water. $31.84 \%$ and $65.24 \%$ are the increment in effectiveness at $1 \%$ nanofraction and $2 \%$ nanofraction with respect to water.

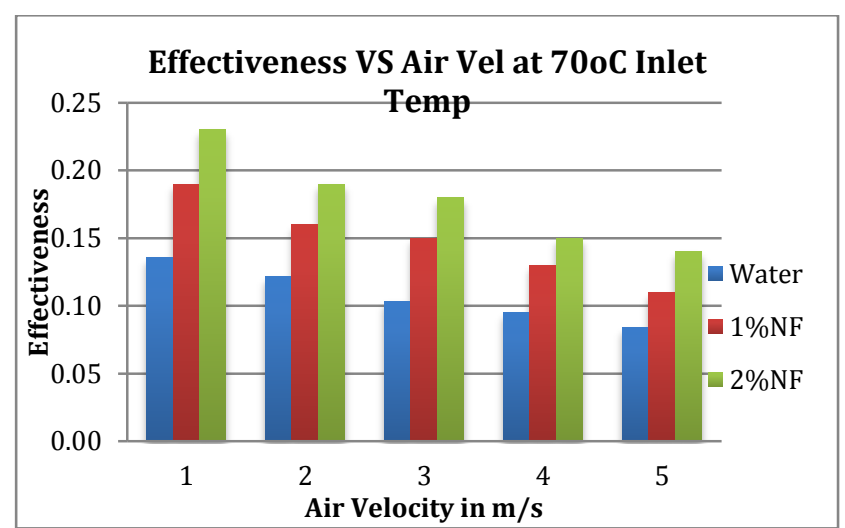

Figure 10 Effectiveness $(€)$ VS Air velocity at $70^{\circ} \mathrm{C}$ inlet gas temp.

The above graph of Effectiveness ( $\epsilon$ ) VS Air velocity at $70^{\circ} \mathrm{C}$ inlet gas temperature shows that as air velocity increases effectiveness decreases. 2\% nanofraction shows better results than $1 \%$ nanofraction and water. $37.16 \%$ and $64.96 \%$ are the increment in effectiveness at $1 \%$ nanofraction and $2 \%$ nanofraction with respect to water.

From figure 07 to 10 it is observed that heat transfer coefficient decreases as inlet temperature and nanofraction increases, this is so because from $40^{\circ} \mathrm{C}$ to $70^{\circ} \mathrm{C}$ inlet temperature, rate at which fluid vaporizes is minimum showing lower boiling limit and at that point vapor pressure is also small.

4.2 Calculation of Heat Gain ( $Q_{\text {gain }}$ ): For various inlet gas temperatures, heat gain at condenser section is 
calculated for thermosyphons heat pipe heat exchanger. Results are plotted effectiveness verses air velocity. Velocity of air at condenser and evaporator section is same and vary as $1 \mathrm{~m} / \mathrm{s}, 2 \mathrm{~m} / \mathrm{s}, 3 \mathrm{~m} / \mathrm{s}, 4 \mathrm{~m} / \mathrm{s}$ and $5 \mathrm{~m} / \mathrm{s}$. Heat gain is calculated for three types of working fluid as water, $1 \%$ nanofluid and $2 \%$ nanofluid.

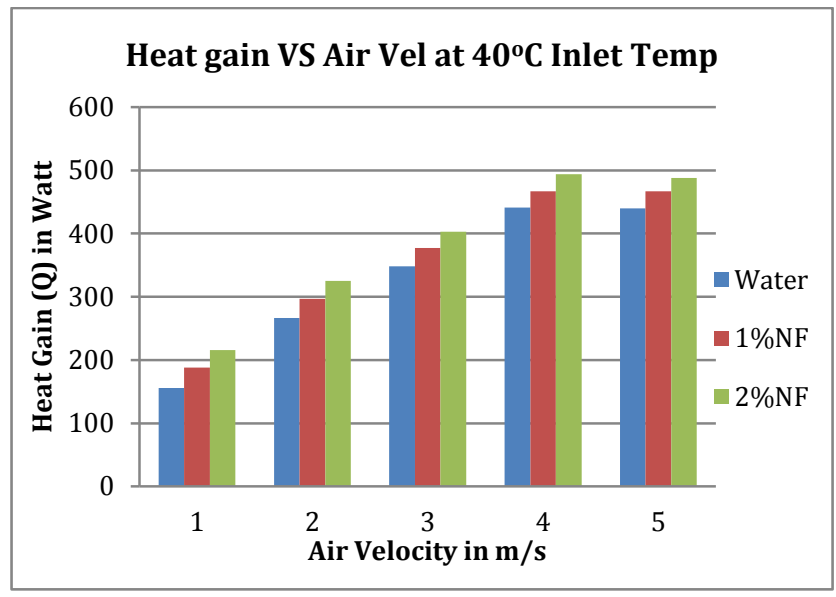

Figure 11 Heat gain (Q) VS Air velocity at $40^{\circ} \mathrm{C}$ inlet gas temp.

The above graph of Heat gain (Q) VS Air velocity at $40^{\circ} \mathrm{C}$ inlet gas temperature shows that as air velocity increases heat gain increases. $2 \%$ nanofraction shows better results than $1 \%$ nanofraction and water. $8.56 \%$ and $16.60 \%$ are the increment in effectiveness at $1 \%$ nanofraction and $2 \%$ nanofraction with respect to water.

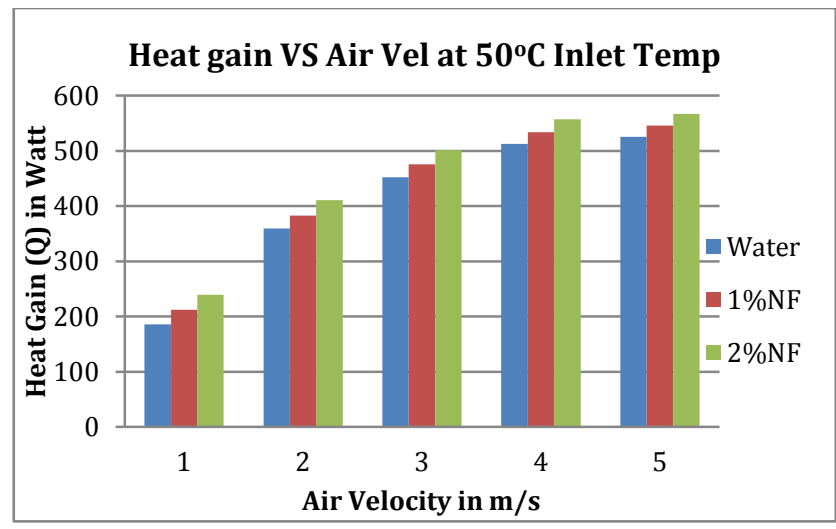

Figure 12 Heat gain (Q) VS Air velocity at $50^{\circ} \mathrm{C}$ inlet gas temp.

The above graph of Heat gain (Q) VS Air velocity at $50^{\circ} \mathrm{C}$ inlet gas temperature shows that as air velocity increases heat gain increases. $2 \%$ nanofraction shows better results than 1\% nanofraction and water. 5.65\% and $11.80 \%$ are the increment in effectiveness at $1 \%$ nanofraction and $2 \%$ nanofraction with respect to water.

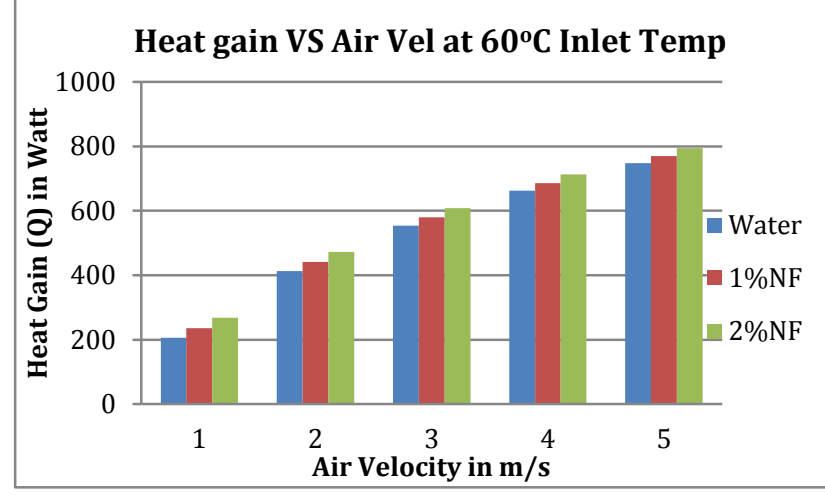

Figure 13 Heat gain (Q) VS Air velocity at $60^{\circ} \mathrm{C}$ inlet gas temp.

The above graph of Heat gain (Q) VS Air velocity at $60^{\circ} \mathrm{C}$ inlet gas temperature shows that as air velocity increases heat gain increases. $2 \%$ nanofraction shows better results than $1 \%$ nanofraction and water. $5.12 \%$ and $10.62 \%$ are the increment in effectiveness at $1 \%$ nanofraction and $2 \%$ nanofraction with respect to water.

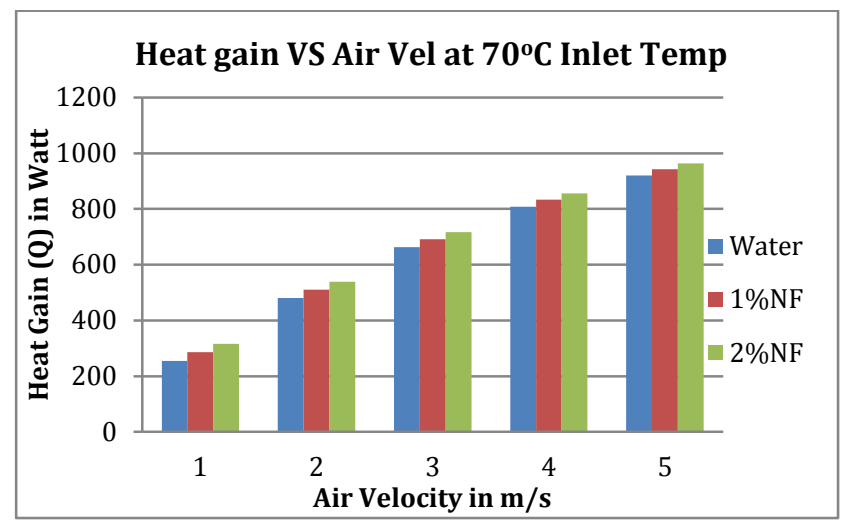

Figure 14 Heat gain (Q) VS Air velocity at $70^{\circ} \mathrm{C}$ inlet gas temp.

The above graph of Heat gain (Q) VS Air velocity at $70^{\circ} \mathrm{C}$ inlet gas temperature shows that as air velocity increases heat gain increases. $2 \%$ nanofraction shows better results than $1 \%$ nanofraction and water. $4.41 \%$ and $8.84 \%$ are the increment in effectiveness at $1 \%$ nanofraction and $2 \%$ nanofraction with respect to water.

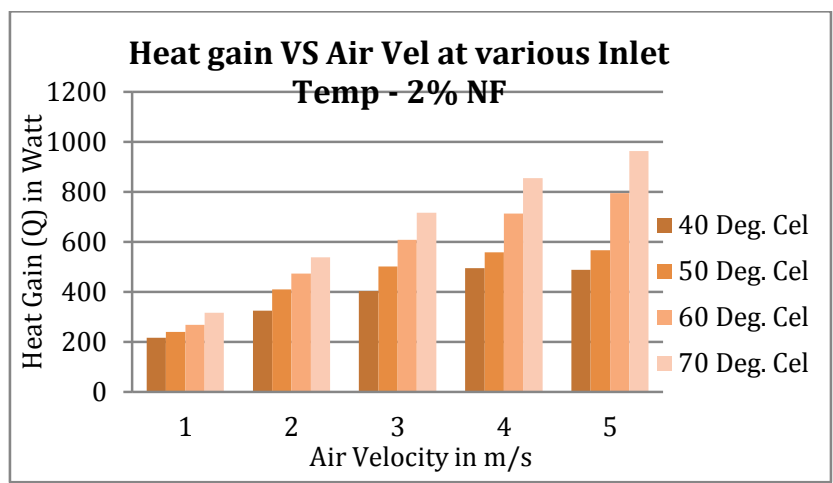

Figure 15 Heat gain (Q) VS Air velocity at 2\%NF. 
The above graph of Heat gain (Q) VS Air velocity at 2\% nanofraction shows that as inlet gas temperature increases heat gain increases. $18.11 \%, 48.30$ and $76.02 \%$ are the increment in effectiveness at $50^{\circ} \mathrm{C}$, $60^{\circ} \mathrm{C}$ and $70^{\circ} \mathrm{C}$ of inlet gas temperature.

\section{Conclusion}

This work investigates the flow and heat transfer phenomena in a thermosyphons heat pipe heat exchanger. Effects of inlet gas temperature, air velocity on heat gain at condenser section and effectiveness are investigated heat flux at evaporator and different working fluid has been also studied. Several important conclusions could be drawn from the present experimentation study and would be presented as follows

Conclusions made on Effectiveness at condenser section:

1) For $40^{\circ} \mathrm{C}$ inlet gas temperature $11.52 \%$ and $27.72 \%$ are the increment in effectiveness at $1 \%$ nanofraction and $2 \%$ nanofraction with respect to water.

2) For $50^{\circ} \mathrm{C}$ inlet gas temperature $34.20 \%$ and $59.55 \%$ are the increment in effectiveness at $1 \%$ nanofraction and $2 \%$ nanofraction with respect to water.

3) For $60^{\circ} \mathrm{C}$ inlet gas temperature $31.84 \%$ and $65.24 \%$ are the increment in effectiveness at $1 \%$ nanofraction and $2 \%$ nanofraction with respect to water.

4) For $70^{\circ} \mathrm{C}$ inlet gas temperature $37.16 \%$ and $64.96 \%$ are the increment in effectiveness at $1 \%$ nanofraction and $2 \%$ nanofraction with respect to water.

Conclusions made on Heat gain at condenser section:

1) For $40^{\circ} \mathrm{C}$ inlet gas temperature $11.52 \%$ and $27.72 \%$ are the increment in heat gain at $1 \%$ nanofraction and $2 \%$ nanofraction with respect to water.

2) For $50^{\circ} \mathrm{C}$ inlet gas temperature $34.20 \%$ and $59.55 \%$ are the increment in heat gain at $1 \%$ nanofraction and $2 \%$ nanofraction with respect to water.
3) For $60^{\circ} \mathrm{C}$ inlet gas temperature $31.84 \%$ and $65.24 \%$ are the increment in heat gain at $1 \%$ nanofraction and $2 \%$ nanofraction with respect to water.

4) For $70^{\circ} \mathrm{C}$ inlet gas temperature $37.16 \%$ and $64.96 \%$ are the increment in heat gain at $1 \%$ nanofraction and $2 \%$ nanofraction with respect to water.

5) For various inlet gas temperature $18.11 \%, 48.30$ and $76.02 \%$ are the increment in heat gain at $50^{\circ} \mathrm{C}$, $60^{\circ} \mathrm{C}$ and $70^{\circ} \mathrm{C}$ of inlet gas temperature.

6) From figure 07 to 10 it is observed that heat transfer coefficient decreases as inlet temperature and nanofraction increases, this is so because from $40^{\circ} \mathrm{C}$ to $70^{\circ} \mathrm{C}$ inlet temperature, rate at which fluid vaporizes is minimum showing lower boiling limit and at that point vapor pressure is also small.

\section{References}

L. E. Smith, The Recovery and Utilization of Heat from Waste Water TN the Home, Applied Energy (1) (1975) p205-214

S.B. Riffat and A. Holt, A Novel Heat Pipe/Ejector Cooler. Pergamon. 19

M. Habert, B. Agostini (2010), Measurement of the performance of a transparent closed loop two-phase thermosyphons, advanced computational methods and experiments in heat transfer XI 227, WIT transactions on Engineering Sci. Vol. 6

G.L. Morrison et al., Water-In-Glass Evacuated Tube solar Water Heaters, School of Mechanical and Manufacturing Engineering, University of New South Wales, Sydney, Australia, 2001

C.E. Heuer, The Application of Heat Pipes on the TransAlaska Pipeline, Special Report 79-26, Cold Regions Research and Engineering Laboratory, US Army Corps of Engineers, Hanover, NH, 197

S. Sorensen et al., Thermal Performance of TAPS Heat Pipes with Non Condensable Gas Blockage. Proceedings of the 11th International Conference on Cold Regions Engineering: Cold Regions Impacts on Transportation and Infrastructure. Anchorage, AK, pp.1-12, 200

L.L. Vasiliev et al., Heat Pipes and Heat Pipe Exchangers for Heat Recovery Systems, Journal of Heat Recovery Systems, vol. 4, pp. 227-233, 1984

K. Ochsner, Carbon Dioxide Heat Pipe in Conjunction with a Ground Source Heat Pump (GSHP), Applied Thermal Engineering, vol. 28, no. 16, pp. 2077-2082, 2008. 